\title{
Duras Mon Amour 2, Saggi italiani su Marguerite Duras, a cura di Edda Melon
}

\section{Emanuele Kanceff}

\section{(2) OpenEdition}

1 Journals

\section{Edizione digitale}

URL: http://journals.openedition.org/studifrancesi/33662

DOI: 10.4000/studifrancesi.33662

ISSN: 2421-5856

\section{Editore}

Rosenberg \& Sellier

\section{Edizione cartacea}

Data di pubblicazione: 1 décembre 2005

Paginazione: 677

ISSN: 0039-2944

\section{Notizia bibliografica digitale}

Emanuele Kanceff, «Duras Mon Amour 2, Saggi italiani su Marguerite Duras, a cura di Edda Melon», Studi Francesi [Online], 147 (XLX | III) | 2005, online dal 30 novembre 2015, consultato il 18 avril 2021. URL: http://journals.openedition.org/studifrancesi/33662 ; DOI: https://doi.org/10.4000/studifrancesi. 33662

Questo documento è stato generato automaticamente il 18 avril 2021.

\section{(c) $(1) \ominus$}

Studi Francesi è distribuita con Licenza Creative Commons Attribuzione - Non commerciale - Non opere derivate 4.0 Internazionale. 


\title{
Duras Mon Amour 2, Saggi italiani su Marguerite Duras, a cura di Edda Melon
}

\author{
Emanuele Kanceff
}

\section{NOTIZIA}

AA. VV., Duras Mon Amour 2, Saggi italiani su Marguerite Duras, a cura di Edda MELoN, Torino, Edizioni Lindau, 2001, pp. 265.

1 La curatrice del volume, prendendo ad exergue una citazione dall'ultimo libro di Marguerite Duras, C'est tout, presenta le giornate di studio da cui è nata la presente raccolta, che è ordinata in diverse parti strutturalmente differenti: Un teatro di voci, Mettere in scena, Leggere la scrittura, Testo teatro film.

2 Paola BAVA, in "L'Eden Cinéma". Voci di un'infanzia coloniale (pp. 13-22), affronta il tema dell'autobiografia negli scritti di Marguerite Duras, mentre Franca BRUERA, Marguerite Duras tra letteratura e teatralità (pp. 23-32) allarga il discorso alle vicende del teatro europeo dopo la Seconda guerra mondiale e di definizione del ruolo e dell'opera della Duras in quel contesto. Prendendo ad esempio Le square, l'A. mostra la reazione della scrittrice all'atmosfera antiletteraria, anticreativa e anticomunicativa che ristagnava con il Nouveau Théâtre. Marie-Ange JOURDAN-GUEYER si occupa di analizzare, in L'Italia dai romanzi al teatro: «Savannah Bay» (pp. 33-38), i contatti della scrittrice con il nostro paese e i contrastanti riflessi di tali esperienze nei suoi scritti e nel teatro. Antonella RAMASOTTO, La voce perduta o il caso di «L'amante anglaise» (pp. 39-52), studia le tre opere tratte dal caso di cronaca di Amélie Rabilloux e del suo crimine misterioso. Rossella XILLovich, «Agatha» o il valzer dei replicanti (pp. 53-59), analizza il breve dialogo pubblicato nel 1981 alle Éditions de Minuit, ispirato a L'Uomo senza qualità di Musil e al Simposio di Platone. Così si conclude la prima parte del libro. Quelle che seguono non sono meno interessanti e ci rammarichiamo veramente di non poterne dare che i titoli. 
3 Nella seconda (Mettere in scena) prendono posto i lavori di Marina BASSANI, La guerra ha $i$ colori dell'infanzia (pp. 63-69), Raul IAIzA, Risuona o ammutolisce. L'incontro con l'opera di Marguerite Duras (pp. 71-82), Maria INVERSI, L'io frantumato del narratore Duras. Un allestimento teatrale (pp. 83-90), Aldo PASQUERO, La memoria senza ricordo. Storie da un'infanzia coloniale (pp. 91-94).

4 Nella terza (Leggere la scrittura) troviamo i saggi di Laura KREYDER, «Ah! Ernesto». Storia di un libro (pp. 97-108), Giuseppe MORRONE, Duras e Bataille. La comicità dell'erotismo (pp. 109-120), Ermanno PEA, Sul mare d'inchiostro nero, la nave Night... (pp. 121-140), Renzo Riccò, Duras, un dolore troppo antico per essere pianto (pp. 141-155).

5 La terza parte (Testo teatro film) ci offre i lavori di Giorgio CERRUTI, «La femme du Gange», un «Tombeau» per L.V.S. (pp. 159-164), Ester Carla de Miro d'AJETA, La mer(e) sauvage, (pp. 165-173), Stefano GRossI, Amare per distruggere, distruggere per amare. Da "L'amant» di Duras a «L'amant» di Annaud (pp. 175-194) e Nadia SETTI, Scrivere la notte ovvero l'abisso della scrittura (pp. 195-203).

6 Segue una ricca Appendice, con interventi di Anna Maria BATTAGLIA (una intervista a Jean Schuster), Edda MELON (La biblioteca di Duras, e, con Ermanno PERA, La biblioteca con Duras), la biografia e la bibliografia della scrittrice. 